\title{
A trajetória brasileira de construção de políticas públicas para a agroecologia
}

\author{
Paulo André Niederle \\ Universidade Federal do Rio Grande do Sul - Porto Alegre - Rio Grande do Sul -
} Brasil

\section{Eric Sabourin}

Centro de Cooperação Internacional em Pesquisa Agronômica para o Desenvolvimento e Universidade de Brasília - Brasília - Distrito Federal - Brasil

\section{Claudia Job Schmitt}

Universidade Federal Rural do Rio de Janeiro - Rio de Janeiro - Rio de Janeiro - Brasil

\section{Mario Lúcio de Ávila}

Universidade de Brasília - Brasília - Distrito Federal - Brasil

\section{Paulo Petersen}

AS-PTA - Agricultura Familiar e Agroecologia e Associação Brasileira de Agroecologia - Rio de Janeiro - Rio de Janeiro - Brasil

\section{William Santos de Assis}

Universidade Federal do Pará - Belém - Pará - Brasil

\begin{abstract}
Resumo
Este artigo analisa a construção de políticas públicas para a agroecologia no Brasil focalizando: (a) o contexto econômico, político e institucional e os processos de organização social que possibilitaram a emergência dessa agenda pública; (b) a constituição de redes de promoção da agroecologia e sua capacidade de influenciar a ação pública; (c) a incorporação do enfoque agroecológico nas políticas públicas considerando a coexistência de distintas concepções de agroecologia. Os resultados são provenientes de uma pesquisa interinstitucional que envolveu diversos pesquisadores e organizações vinculadas à Rede Políticas Públicas e Desenvolvimento Rural na América Latina (PP-AL). Os mesmos apontam que a construção de políticas a favor da agroecologia ganhou espaço a partir de 2002, quando a eleição do presidente Lula levou para dentro da estrutura do Estado atores com interface direta com movimentos sociais e sindicais. Na ampla coalizão política que se formou no novo governo e, sobretudo, no Ministério do Desenvolvimento Agrário (MDA), predominaram movimentos agrários com suas tradicionais pautas em torno do crédito rural e da reforma agrária. No entanto, eles passaram a conviver com um movimento agroecológico cada vez mais expressivo e organizado, o que levou à incorporação gradual de referenciais socioambientais nas políticas agrícolas diferenciadas. Além disso, esta
\end{abstract}


convergência foi potencializada pela agenda da segurança alimentar e nutricional, a qual cumpriu um papel decisivo na disseminação da agroecologia como referencial de política pública.

Palavras-Chave: Agroecologia. Políticas Públicas. Agricultura familiar.

\section{The Brazilian trajectory of construction of public policies for agroecology}

\section{Abstract}

This article analyzes the construction of public policies for agroecology in Brazil focusing on: (a) the economic, political and institutional context and the processes of social organization that enabled the emergence of this public agenda; (b) the creation of networks to promote agroecology with capacity to influence public action; (c) the incorporation of the agroecological approach in public policies considering the coexistence of different conceptions of agroecology. Results come from an interinstitutional research that involved several researchers and organizations linked to the Public Policy and Rural Development Network in Latin America (PP-AL). They point out that the construction of policies in favor of agroecology gained space after 2002, when the election of President Lula took to the structure of the State actors with direct interface with social movements and unions. In the broad political coalition that was formed in the new government and especially in the Ministry of Agrarian Development (MDA), agrarian movements predominated, as well as their traditional demands of rural credit and agrarian reform. However, they faced an increasingly expressive and organized agroecological movement, which forced the gradual incorporation of socio-environmental references in differentiated agricultural policies for rural development. In addition, this convergence was strengthened by the food and nutritional security agenda, which played a decisive role in the dissemination of agroecology as a reference for public policy.

Keywords: Agroecology. Public policies. Family farming.

\section{La trayectoria brasileña de construcción de políticas públicas para la agroecología}

\section{Resumen}

Este artículo analiza la construcción de políticas públicas para la agroecología en Brasil enfocando: (a) el contexto económico, político e institucional y los procesos de organización social que posibilitaran la emergencia de esa agenda pública; (b) la constitución de redes de promoción de la agroecología y su capacidad de influir en la acción pública; (c) la incorporación del enfoque agroecológico en las políticas públicas considerando la coexistencia de distintas concepciones de agroecología. Los resultados provienen de una investigación interinstitucional que involucró a diversos investigadores y organizaciones vinculadas a la Red Políticas Públicas y Desarrollo Rural en América Latina (PP-AL). Los mismos apuntan que la construcción de políticas a favor de la agroecología ganó espacio a partir de 2002, cuando la elección del presidente Lula llevó a dentro de la estructura del Estado actores con interfaces directas con movimientos sociales y sindicales. En la amplia coalición política que se formó en el nuevo gobierno y, sobre todo, en el Ministerio de Desarrollo Agrario (MDA), predominaron movimientos agrarios con sus tradicionales pautas en torno al crédito rural y la reforma agraria. Sin embargo, estos pasaron a convivir con un movimiento agroecológico cada vez más expresivo y organizado, lo que llevó a la incorporación gradual de referencias socioambientales en las políticas agrícolas diferenciadas. Además, esta convergencia fue potenciada por la agenda de la seguridad alimentaria y nutricional, la cual cumplió un papel decisivo en la diseminación de la agroecología como referencial de política pública.

Palabras-Clave: Agroecology. Public policies. Family farming. 


\section{Introdução}

O Brasil é internacionalmente reconhecido como um dos países que mais avançou na construção de políticas públicas para a agroecologia. Parte deste sucesso está associada com a trajetória de movimentos sociais, sindicais, profissionais e estudantis que, desde os anos 1970, impulsionaram discussões e práticas vinculadas à agricultura alternativa. Em virtude da crescente capacidade de articulação em rede destes atores, eles conseguiram levar a agroecologia para dentro da agenda do Estado, impactando, sobretudo, os referenciais que orientaram a construção de políticas para a agricultura familiar. Mesmo assim, este processo foi cercado de controvérsias e limites, o que é resultado, dentre outras coisas, da coexistência de atores com interesses e concepções distintas com relação à agroecologia e seu potencial para orientar processos mais amplos de transição nos sistemas agroalimentares e nas dinâmicas de desenvolvimento rural.

A construção de políticas de promoção da agroecologia culminou com a criação, em 2012, da Política Nacional de Agroecologia e Produção Orgânica (PNAPO), instrumentalizada em 2013 pelo I Plano Nacional de Agroecologia e Produção Orgânica (I PLANAPO), atualizado e revisado em 2016 (II PLANAPO). No entanto, o percurso que ensejou a construção desta política nacional encontra suas raízes em um conjunto diferenciado de iniciativas de base local, desenvolvidas nas diferentes regiões do Brasil, sobretudo a partir do final dos anos 1970, por um universo heterogêneo de organizações não governamentais, em parceria com movimentos sociais e organizações de agricultores familiares (Sambuichi et al., 2017). Este processo foi intensificado na década de 1990 em virtude da multiplicação de redes locais e territoriais de gestão do conhecimento agroecológico, fundadas na capacitação de agricultores e técnicos e na experimentação mútua ou compartilhada. Além disso, ampliaram-se os esforços de diálogo entre sociedade civil e governos, dando origem a uma pluralidade de dinâmicas de institucionalização da agroecologia. Essa rede de atores passou a influenciar a construção e articulação de diferentes instrumentos de políticas públicas, processo este que ganhou maior expressividade em virtude da centralidade assumida pela temática da Segurança Alimentar e Nutricional (SAN) na agenda governamental nos últimos quinze anos.

Este artigo analisa a experiência brasileira de construção de políticas públicas em favor da agroecologia em um horizonte de tempo que vai de suas origens, nas décadas de 1980 e 1990, até o fim do segundo mandato da Presidenta Dilma Rousseff, encerrado em 2016. Os resultados provêm de uma pesquisa interinstitucional coordenada pela Rede Políticas Públicas e Desenvolvimento Rural na América Latina (PP-AL). ${ }^{1}$ O referencial teórico considerou os processos de construção de instrumentos favoráveis a agroecologia cruzando a sociologia da ação pública (Hassenteufel, 2008), em particular o papel de múltiplos atores da sociedade civil e de diversos setores de governo (Pierson, 2016), e a análise institucional, em termos de trajetória e processos de institucionalização das políticas (Mahoney e Rueschmeyer, 2003; Pierson e Sckocpol, 2008). A grade de análise comum enfatizou as seguintes variáveis: i) o papel das ideias e dos conceitos na emergência ou nas

\footnotetext{
${ }^{1}$ Ver SABOURIN, E.; PATROUILLEAU, M.; Le COQ, J-F.; VASQUEZ, L.; NIEDERLE, P. (Orgs.) . Políticas públicas a favor de la agroecología em América Latina y El Caribe. Porto Alegre: Evangraf, Red PP-AL, FAO, 2017.
} 
mudanças das políticas (Surel, 1998; Palier e Surel, 2005), constituindo o cimento das coalizões de causas que influenciam nas decisões de políticas (Sabatier e JenkinsSmith, 1993; Weible et al., 2009); ii) os eventos chaves que levam a mudanças institucionais criando bifurcações (Mahoney e Thelen, 2010); iii) o papel dos grupos de interesse (movimento social, sindicatos, empresas) e as suas capacidades para criar alianças para influir nas decisões públicas (Surel, 1998; Weible et al., 2009).

Primeiramente, o artigo discute o contexto político-institucional e os processos de organização social que possibilitaram a institucionalização da agroecologia como um enfoque de análise de política pública. Em segundo lugar, apresenta os principais instrumentos de intervenção governamental mobilizados em favor da agroecologia, considerando seu conteúdo, desenho institucional, mecanismos de articulação e efeitos potenciais.

\section{A construção das redes de agroecologia}

A construção de políticas públicas em favor da agroecologia envolveu uma ampla rede de atores estatais e não estatais. A formação dessa rede ocorreu, principalmente, a partir dos anos 1980, junto às lutas por reabertura democrática, mudança dos referenciais de ação do Estado e ampliação do protagonismo da sociedade civil. Assim como em outros países latino-americanos, a promoção da agroecologia no Brasil esteve diretamente vinculada à ação dos movimentos sociais ligados à pequena agricultura familiar e camponesa. Isso fez com que o termo assumisse uma conotação não apenas técnica, mas eminentemente política, mantendo níveis diferenciados de articulação com diferentes modelos de "agricultura alternativa", ou, para usar um termo mais contemporâneo, "agriculturas de base ecológica" - aí compreendidas quase todas as formas de produção que adotam uma perspectiva crítica aos preceitos da modernização conservadora que orientaram a ação do Estado brasileiro desde, pelo menos, meados dos anos $1960^{2}$.

Um dos principais marcos originários deste processo foram os Encontros Brasileiros de Agricultura Alternativa - EBAAs realizados nos anos 1980 (1981, 1984, 1987 e 1989). Inicialmente caracterizados como "espaços técnicos" (em pleno regime militar), e protagonizados por agrônomos vinculados à Federação de Associações dos Engenheiros Agrônomos do Brasil (FAEAB), ao longo do processo de democratização eles foram sendo crescentemente ocupados pelos movimentos estudantis e sindicais, assumindo também um caráter mais político (Weid, 1988; Luzzi, 2007). A partir deles, atores com ações geralmente pontuais e desarticuladas começaram a tecer uma rede cada vez mais ampla, em escala nacional, o que potencializou reflexões, críticas e ações coletivas (Petersen et al., 2013). Esse processo de articulação envolvendo diferentes atores e iniciativas no campo da chamada agricultura alternativa possibilitou um importante ganho em escala para experiências localizadas, com trajetórias e desdobramentos distintos nas várias regiões do país.

Na região Nordeste, por exemplo, a questão tecnológica já se fazia presente, desde final dos anos 1970, como uma problemática a ser enfrentada pelos

\footnotetext{
2 É possível incluir, nesse rol, a agricultura orgânica, a agricultura ecológica, a agricultura biodinâmica, a agricultura natural, a permacultura, as distintas "escolas" de manejo de sistemas agroflorestais, entre outras.
} 
camponeses do semiárido, repercutindo na atuação de ONGs, como a Federação de Órgãos para Assistência Social e Educacional (FASE), o Movimento de Organização Comunitária (MOC-BA) e o Programa de Aplicação de Tecnologias Apropriadas às Comunidades (PATAC), bem como no trabalho desenvolvido pela Comissão Pastoral da Terra (CPT) junto às comunidades rurais (Dias, 2004) (Leroy e Abramovay, 1998). Por sua vez, no caso da região Norte, a crítica ao processo de modernização da agricultura e seus impactos na região esteve fortemente associada às lutas dos camponeses e povos e comunidades tradicionais em defesa de seus territórios, guardando também relação com o trabalho desenvolvido por setores progressistas da Igreja Católica inspirados pela Teologia da Libertação, no apoio a estes processos de organização social. A partir da década de 1980, as lutas dos seringueiros, povos indígenas e camponeses da Amazônia possibilitaram um novo tipo de articulação entre luta social e luta ambiental. No que se refere especificamente à produção agrícola, verifica-se, também na Amazônia o surgimento de programas de extensão rural e ONGs de assessoria voltados ao desenvolvimento e disseminação de práticas agrícolas alternativas.

Por sua vez, no Sul e Sudeste, onde o processo de modernização havia sido mais intenso, verificou-se, desde os anos 1970, a emergência de iniciativas locais que buscavam se contrapor à narrativa predominante relacionada à agricultura moderna por meio da experimentação de práticas inovadoras de produção, conservação dos solos, controle biológico, entre outras. Em São Paulo em 1973-1974 organizou-se, em Botucatu, a Estância Demétria, inspirada pelos princípios da agricultura biodinâmica. Esta experiência teve como desdobramento uma série de ações relacionadas à disseminação da agricultura biodinâmica no Brasil, incluindo aí a criação da Associação Brasileira de Agricultura Biodinâmica em 1995 e da Associação de Certificação Instituto Biodinâmico em 1999. Registra-se também, nestas regiões do país, uma ampliação, sobretudo a partir da segunda metade da década de 1970, das lutas dos movimentos sociais e da ação pastoral vinculada tanto à Igreja Católica como à Igreja Evangélica de Confissão Luterana no Brasil (IECLB). Diversas ONGs e sindicatos de trabalhadores rurais (STRs), passaram a articular em sua intervenção junto às comunidades rurais a "questão tecnológica", o estímulo ao associativismo e um trabalho permanente de educação popular. No final da década de 1990 e início dos anos 2000, as redes de agroecologia com atuação nestas regiões, entre elas a Rede Ecovida de Agroecologia, assumiriam um papel de destaque na formulação da legislação brasileira que regulamenta os sistemas orgânicos de produção.

No Centro Oeste, as lutas pela terra desempenharam também um papel importante na trajetória das organizações engajadas na promoção da agroecologia. Em 1992, por ocasião da Conferência das Nações Unidas sobre o Meio Ambiente e o Desenvolvimento (Eco-92), foi constituída a Rede Cerrado, composta atualmente por cerca de 600 organizações envolvendo ambientalistas, entidades não governamentais com atuação no campo da agroecologia e organizações representativas de povos e comunidades tradicionais. Entre as atividades da Rede destaca-se a organização, a partir de 2002, das diversas edições do evento denominado "Encontro e Feira dos Povos do Cerrado" (Farranha e Santos, 2015).

Em âmbito nacional, em 1983 foi criado o Projeto PTA, vinculado à FASE e desenvolvido com o apoio da cooperação internacional, tendo como objetivo pesquisar tecnologias alternativas e divulgá-las aos pequenos produtores (Leroy e 
Abramovay, 1998). O Seminário de Campinas-SP, promovido pelo Projeto no final deste mesmo ano, chegou a congregar mais de 40 organizações, incluindo entidades de apoio e assessoria, STRs, uma federação sindical, representantes de órgãos públicos e entidades profissionais. Tratava-se, naquele momento, de "discutir a situação da pequena produção no campo, a necessidade de buscar alternativas tecnológicas e a criação de uma articulação nacional ao redor dessa questão" (Leroy e Abramovay, 1998, p. 5). A rede de organizações que se constituiu a partir do seminário conseguiu agregar, inicialmente, experiências situadas em dez estados brasileiros, nas regiões Sul, Sudeste e Nordeste do país, fomentando, em muitos locais, a criação de Centros de Tecnologias Alternativas (CTAs) (Dias, 2004; Luzzi, 2007; Leroy e Abramovay, 1998). No final da década de 1980, em um contexto de restruturação do Projeto PTA, que deixou de operar como uma estrutura organizativa administrativamente vinculada à FASE, verifica-se a criação de diferentes ONGs autônomas com atuação no campo da agroecologia. Entre elas cabe mencionar a Assessoria e Serviços a Projetos em Agricultura Alternativa (AS-PTA), que se manteve, historicamente, como um ator-chave na estruturação da rede em nível nacional.

As organizações vinculadas ao Projeto PTA e demais entidades voltadas à promoção de uma agricultura alternativa abrigavam jovens profissionais de ciências agrárias, muitos dos quais egressos dos movimentos estudantis e dos Grupos de Agricultura Ecológica (GAEs), que haviam se formado nas universidades ao longo dos anos 1980. Estes jovens profissionais trouxeram para dentro das organizações, referências que gradualmente adentravam no mundo acadêmico, sobretudo no campo das ciências agrárias. Destaca-se, neste sentido, a tradução, em 1989, do livro organizado por Miguel Altieri, intitulado Agroecologia: as bases científicas da agricultura alternativa (Altieri, 1989). Ao mesmo tempo, retroalimenta-se o debate teórico e político dos movimentos estudantis com os resultados das experiências empíricas.

No que tange especificamente aos movimentos agrários e ao sindicalismo rural - os quais protagonizaram as lutas sociais pela reforma agrária e pelo reconhecimento e legitimação da agricultura familiar e camponesa - a adoção da agroecologia como referencial de ação revelou-se um processo gradual, contraditório e ainda incompleto. O termo esteve longe de constituir um consenso dentre estes movimentos. No começo da década de 1990, no curso das lutas que levaram à criação do PRONAF, e que contaram com uma forte participação de organizações sindicais com atuação na Região Sul do Brasil, a maioria dos movimentos sociais e sindicais rurais concentrava suas pautas na desigualdade do acesso aos fatores de produção (terra, capital e insumos). As discussões estavam menos associadas à transformação do modelo produtivo, do que à exclusão da pequena agricultura dos recursos públicos e dos mercados agrícolas e essa dinâmica se refletia na estrutura do próprio MDA.

No caso do Movimento de Trabalhadores Rurais Sem Terra (MST), foi somente durante seu $4^{\circ}$ Congresso Nacional, em 2000, que o mesmo adotou a agroecologia como linha política de ação, tornando-se, a partir daí, um dos principais promotores do novo modelo, inclusive investindo na formação de técnicos em escolas próprias (Barcellos, 2014). A partir de 2002, o MST passou a promover, anualmente, as Jornadas de Agroecologia, entendidas pelo movimento como um espaço de 
formação, mobilização e troca de experiências, reunindo um público aproximado de 3.000 participantes por edição, incluindo agricultores, pesquisadores e profissionais de diferentes áreas. Por sua vez, na Confederação Nacional dos Trabalhadores na Agricultura (CONTAG) e na Federação Nacional dos Trabalhadores e Trabalhadoras na Agricultura Familiar (FETRAF), o debate foi ainda mais controverso, tendo sido parcialmente bloqueado pelas resistências de uma base social mais integrada ao modelo convencional (embora isso também seja válido para uma parcela da base social da própria Via Campesina). Verifica-se, no entanto, em ambas as organizações, um forte engajamento das mulheres no debate relacionado à agroecologia, em estreita conexão com uma agenda mais ampla envolvendo os direitos das mulheres sob uma perspectiva feminista.

E se hoje existe certa convergência entre as lideranças das organizações agroecológicas e dos principais movimentos sociais e sindicais do país, a "ecologização dos modelos produtivos" ainda é um tema latente nas discussões sobre as estratégias e as políticas de desenvolvimento rural defendidas por diferentes atores deste campo político (Picolotto e Brandenburg, 2015). Parte dessas discussões, e dos entendimentos que foram obtidos, deve-se a um novo espaço de diálogo entre movimentos, organizações sociais, acadêmicos e gestores públicos convidados, os Encontros Nacionais de Agroecologia (ENAs, 2002, 2006 e 2014). A organização dos mesmos tem sido liderada pela Articulação Nacional de Agroecologia (ANA), um movimento criado em 2002, que se articula com outros movimentos tais quais o Fórum Brasileiro de Economia Solidária (FBES), a Rede Brasileira de Justiça Ambiental (RBJA), a Rede Alerta contra o Deserto Verde (RADV), a Associação Brasileira de Pós-Graduação em Saúde Coletiva (Abrasco), a Associação Brasileira de Agroecologia (ABA), o Fórum Brasileiro de Soberania e de Segurança Alimentar e Nutricional (FBSSAN), a Marcha Mundial de Mulheres (MMM) e a Articulação de Mulheres Brasileiras (AMB), criando uma ampla rede social com capacidade não apenas para incidir sobre a formulação de políticas públicas, mas para articular o referencial da agroecologia com outros referências de ação pública, tais como aqueles da segurança alimentar e nutricional, da luta pela terra e do feminismo.

Chama atenção nessa trajetória a emergência, no universo de atuação das organizações sociais anteriormente mencionadas, de uma diversidade de expressões da agroecologia. Consideradas nas suas diferentes nuances, estas distintas perspectivas têm em comum uma visão abrangente das transformações econômicas, sociais, ecológicas e culturais associadas à chamada "transição para a agroecologia", buscando se contrapor, pelo menos do ponto de vista discursivo, às abordagens propugnadas por alguns setores ligados à agricultura orgânica, centradas, antes de mais nada, na conversão técnica dos sistemas produtivos. O que não significa que a certificação orgânica não seja percebida, por muitos desses atores, como uma estratégia válida de acesso aos mercados.

\section{A incorporação do enfoque agroecológico aos instrumentos de políticas públicas}

Os caminhos que possibilitaram a tradução (ou transcodificação) (Lascoumes, 1997) da visão de agroecologia construída, historicamente, pelas redes de organizações sociais em um enfoque capaz de influenciar a formulação e implementação de políticas públicas foram sendo traçados em um processo descontínuo e, em alguma medida, disperso, que atravessou diferentes arenas e 
espaços de interação social. No caso brasileiro, as políticas em favor da agroecologia avançaram, em boa medida, no espaço político e institucional aberto pelas políticas de fortalecimento da agricultura familiar. Ao adentrar o universo destas políticas públicas, as ideias agroecológicas passaram a interagir com dispositivos préexistentes, enfrentando resistências e sofrendo adaptações. Nesta seção buscaremos, portanto, explorar as interfaces estabelecidas ao longo do tempo entre as ideias agroecológicas e um conjunto heterogêneo de instrumentos de políticas públicas em favor da agroecologia, considerando, no entanto, que muitos deles não foram estruturados, originalmente, a partir de um enfoque agroecológico. Procuramos explorar, além disso, os desafios envolvidos na coordenação e articulação desses instrumentos na perspectiva da agroecologia.

Apesar da crescente repercussão que os debates sobre "sustentabilidade" angariavam no Brasil (vide Conferência Rio 92), chama atenção o fato de que importantes acúmulos gerados no âmbito do Programa Piloto para a Proteção das Florestas Tropicais do Brasil (PPG7) e, particularmente, pelo Subprograma Projetos Demonstrativos (PDA), tendo como foco a conservação e manejo da biodiversidade e o desenvolvimento de atividades sustentáveis nas florestas tropicais brasileiras, não tenham sido incorporados de forma mais expressiva pelas políticas de desenvolvimento rural forjadas nos anos $1990^{3}$. O PDA possibilitou a participação de redes de organizações da sociedade civil, a exemplo do Grupo de Trabalho Amazônico (GTA), da Rede Mata Atlântica e das organizações ligadas à já mencionada Rede PTA, na implementação de um programa voltado ao manejo sustentável dos biomas Amazônia e Mata Atlântica. O mesmo tinha como objetivo contribuir para a experimentação, adaptação e disseminação de abordagens inovadoras de desenvolvimento sustentável, sendo implementado por organizações comunitárias e ONGs, mas, também, eventualmente, por governos municipais.

O programa operava através de chamadas públicas, contemplando, em seu escopo, o financiamento a atividades voltadas ao manejo florestal, capacitação, fortalecimento das organizações sociais, processamento de produtos da sociobiodiversidade, entre outras. Ainda que as referências específicas à agroecologia fossem bastante pontuais, predominando um discurso mais abrangente em torno do desenvolvimento sustentável, o conteúdo do programa e seu formato extremamente flexível e adaptável de implementação, encontrou uma grande aderência junto às redes de agroecologia, fortalecendo não apenas as experiências locais, mas a articulação em rede dessas iniciativas. No que diz respeito especificamente às políticas públicas, o PDA serviu como referência para a criação de programas e ações governamentais em âmbito municipal e estadual, impulsionando também a criação, na região Norte, do Programa de Desenvolvimento Socioambiental da Produção Familiar Rural (Proambiente), o qual articulava em uma mesma ferramenta de intervenção um leque diferenciado de ações: planejamento territorial, assistência técnica e extensão rural, certificação e pagamento de serviços ambientais, entre outras (Mattos, 2011, p. 733-735).

\footnotetext{
${ }^{3}$ O PPG7 tinha como foco o manejo da biodiversidade e o desenvolvimento de atividades sustentáveis nas florestas tropicais brasileiras, contando com forte apoio da cooperação internacional, sobretudo alemã. Gerou resultados bastante significativos no que diz respeito à criação de unidades de conservação, corredores ecológicos, demarcação de terras indígenas e implantação de reservas extrativistas nos biomas Amazônia e Mata Atlântica.
} 
Ao largo destas experiências, o Programa Nacional de Fortalecimento da Agricultura Familiar (PRONAF) institucionalizou-se, a partir de meados dos anos 1990, como o carro-chefe das políticas voltadas à agricultura familiar, mantendo essa posição nas décadas subsequentes, com significativa ampliação do volume total de recursos investidos em suas operações, a partir de 2003. O Programa consolidou, ao longo de sua história, uma estrutura voltada para o financiamento, com taxas de juros e condições diferenciadas de pagamento, para operações de crédito de custeio e investimento desenvolvidas no âmbito da agricultura familiar incluindo: custeio da safra e de atividades de processamento, investimento em máquinas agrícolas e equipamentos, infraestrutura de produção e serviços agropecuários, entre outras linhas de atuação.

Ao longo do tempo, o PRONAF incorporou uma série de inovações resultantes das demandas apresentadas por diferentes grupos sociais. No momento da sua criação, em 1995, o Programa concentrava sua atuação, fundamentalmente, no financiamento da produção agrícola, através de operações de custeio e investimento. Em 1996, passou a contemplar, no âmbito do chamado PRONAF Infraestrutura, recursos destinados à implantação de equipamentos de infraestrutura e serviços básicos municipais, bem como para a capacitação de agricultores, conselheiros municipais e equipes técnicas responsáveis pelos chamados Planos Municipais de Desenvolvimento Rural (PMDRs). Em 1997 verifica-se a criação do chamado "Pronafinho", uma linha especial de custeio direcionada aos agricultores menos capitalizados, marcando a emergência de uma segunda geração de políticas voltadas à agricultura familiar, influenciadas por uma perspectiva socioassistencial.

Ainda que o PRONAF tivesse, como um de seus objetivos gerais, a promoção do desenvolvimento sustentável, procurando, sobretudo por meio da linha Infraestrutura e Serviços, assumir os contornos de uma política de desenvolvimento rural, não conseguiu se afirmar como uma ferramenta capaz de impulsionar um modelo técnico-produtivo voltado à promoção de sistemas produtivos de base ecológica (creio que devíamos citar alguém aqui). As iniciativas nessa direção podem ser identificadas, sobretudo a partir do primeiro governo Lula. Nesse sentido, particularmente a partir do Plano Safra 2003/2004, verifica-se um esforço de incorporação ao PRONAF de linhas específicas que visavam financiar atividades voltadas à promoção da agroecologia e da agricultura orgânica e ao manejo sustentável dos agroecossistemas, a exemplo do PRONAF Semiárido, PRONAF Floresta, PRONAF Agroecologia (2005/2006), PRONAF Eco (2007/2008), PRONAF Sistêmico (2008/2009).

Todavia, estas linhas de crédito diferenciadas têm sido acessadas por um número muito reduzido de agricultores familiares e, sobretudo, muito pouco promovidas pelas instituições de ATER e os bancos públicos (Sambuichi e Oliveira, 2011). O Programa apresentou, também, no curso de sua história, uma série de limites no sentido de incorporar os segmentos mais empobrecidos da agricultura familiar e desconcentrar a aplicação de recursos - concentrados em aproximadamente 50\% na região Sul do país (Grisa, 2017). A maioria dos projetos continuou, ao longo dos governos FHC, Lula e Dilma Rousseff, a financiar commodities tradicionais, sobretudo o milho, a soja, o café e o fumo, produzidas com base nas chamadas tecnologias modernas disseminadas a partir da Revolução Verde (Grisa, 2017). Assim, a dificuldades enfrentadas pelo PRONAF no atendimento aos segmentos mais 
empobrecidos da agricultura familiar contribuíram para que os movimentos sociais, com vieses e ênfases distintas, passassem a questionar a estrutura geral do programa, sua orientação produtivista e suas limitações no sentido de se adequar às múltiplas realidades vivenciadas pela agricultura familiar.

Com o início do primeiro governo Lula, em 2003, formou-se um ambiente político e institucional mais favorável à circulação das ideias agroecológicas. Destacase, nesse novo contexto, a centralidade adquirida pelas questões relacionadas ao combate à fome e à SAN, com o lançamento do Programa Fome Zero; o fortalecimento de espaços institucionais de interlocução Estado-Sociedade Civil, em que se destacam os Conselhos e as Conferências Nacionais, contemplando também, como apontam Pires e Vaz (2014), uma grande diversidade de grupos de trabalho, comitês consultivos, mesas de negociação e reuniões ${ }^{4}$; e a construção de uma nova geração de instrumentos de políticas públicas dirigidos à agricultura familiar.

Neste contexto, o Conselho Nacional de Segurança Alimentar e Nutricional (CONSEA) constituiu-se como um espaço estratégico de elaboração de um novo referencial de política pública orientado por princípios de Soberania e Segurança Alimentar e Nutricional (SSAN). Este fórum ampliou as possibilidades de articulação prática e discursiva entre "o fortalecimento da agricultura familiar", "o Direito Humano à uma Alimentação Saudável e Adequada" e a "agroecologia". O Conselho de Desenvolvimento Rural Sustentável, estruturado em 1999 e reformulado em 2003 , também se fortaleceu como um espaço de diálogo em torno do tema da agroecologia, chegando a criar um comitê específico referente a esta temática. Os debates protagonizados nestes espaços contribuíram para o alinhamento de atores e a agregação de posições difusas no âmbito das redes de ação pública com atuação no campo da agroecologia, colocando em interação recursos intelectuais e práticos e categorias de conhecimento e de intervenção pertencentes a setores distintos (Lascoumes, 1996). No caso do CONSEA, os diálogos estabelecidos com as áreas da saúde, nutrição, assistência social, economia solidária, entre outras, contribuíram para fortalecer o caráter intersetorial, não apenas da SAN, mas também da agroecologia, o que posteriormente se revelou na PNAPO.

Embora muitos dos novos instrumentos de política pública voltados ao fortalecimento da agricultura familiar criados a partir de 2003, a exemplo do Programa de Garantia de Preços da Agricultura Familiar (PGPAF) e do Seguro da Agricultura Familiar (SEAF), representaram, fundamentalmente, um aperfeiçoamento do PRONAF, não produzindo alterações importantes na perspectiva da incorporação da agroecologia, outros produziram inflexões significativas, rompendo com um referencial meramente produtivista. Neste sentido podem-se destacar os programas de desenvolvimento territorial, de extensão rural e pesquisa agropecuária, de compras governamentais de alimentos e de adaptação dos sistemas produtivos às condições ecológicas locais.

\footnotetext{
${ }^{4}$ A construção de espaços de interlocução Estado-Sociedade Civil encontra suas raízes no processo de democratização do país e na consolidação, na Constituição Federal de 1988, de uma série de dispositivos que buscaram institucionalizar mecanismos de controle social e ampliar a capacidade de influência dos cidadãos na sua relação com as políticas públicas. Esse processo é anterior portanto, aos governos Lula e Dilma, mas se intensifica nessas administrações. Ver, por exemplo, Avritzer (2008) e Pires e Vaz (2014).
} 
Em 2003, sob pressão dos movimentos sociais do campo, foi criada a Secretaria de Desenvolvimento Territorial (SDT), junto ao MDA, visando potencializar um enfoque transversal, participativo e supra municipal às políticas de desenvolvimento rural. Nesta direção, ainda em 2003, foram criados o Programa de Apoio à Infraestrutura nos Territórios Rurais (PROINF) e o PRONAT (Programa Nacional de Desenvolvimento Territorial), com o objetivo de articular políticas públicas e orientar a elaboração de projetos de infraestrutura e serviços no âmbito dos territórios rurais. Foram instituídos espaços de participação em nível territorial, os Colegiados Territoriais, que conseguiram, em territórios onde existiam demandas nessa direção, formular propostas de promoção da agroecologia (infraestruturas de comercialização para feiras e cooperativas, capacitação, processamento de produtos, entre outras ações).

Ainda em 2003, o Departamento de Assistência Técnica e Extensão Rural (DATER) foi transferido para o MDA5 , ficando sob a responsabilidade da Secretaria de Agricultura Familiar (SAF). Desta forma, teve início o processo de elaboração da Política Nacional de Assistência Técnica e Extensão Rural (PNATER), que entrou em vigor em 2004. A PNATER voltou-se exclusivamente à agricultura familiar e aos agricultores atendidos pelas políticas de reforma agrária, determinando que as ações desenvolvidas deveriam estar ancoradas em uma abordagem interdisciplinar e multidisciplinar, estimulando a adoção de metodologias participativas e de "um paradigma tecnológico baseado nos princípios da Agroecologia" (BRASIL/MDA, 2004, p. 7). Além disso, a política teve como marca importante a incorporação ao Sistema Nacional de ATER de um conjunto significativo de ONGs, as quais passaram a acessar recursos para a implantação de programas e ações voltados, em muitos casos, à promoção da agroecologia. Em 2010, um novo instrumento jurídico (Lei 12.188/2010) passou a orientar a contratação destas ONGs e, à rigor, de todas as organizações públicas e privadas vinculadas ao sistema de ATER. ${ }^{6}$ As Chamadas Públicas delimitaram área de atuação, número de agricultores atendidos, metodologia e produtos a serem apresentados pelos prestadores de serviços de ATER (Diesel et al., 2015). Nesta perspectiva, o MDA passou a lançar chamadas especificamente dirigidas à promoção da "Agricultura Sustentável" e da "Agroecologia". 7

No que tange à pesquisa agropecuária, cabe destacar o modo como a Empresa Brasileira de Pesquisa Agropecuária (Embrapa), ligada ao MAPA, e cujas capacidades institucionais foram historicamente direcionadas para a implementação de agendas de pesquisa voltadas, prioritariamente, ao desenvolvimento das cadeias produtivas do agronegócio, introduziu importantes inovações na direção de pesquisas em sistemas agroecológicos. Em parceria com outros Ministérios e com diferentes

\footnotetext{
${ }^{5}$ Anteriormente o DATER estava sob a tutela do Ministério da Agricultura, Pecuária e Abastecimento (MAPA).

${ }^{6}$ As duas mudanças mais significativas foram a alteração da Lei 8.666 de 21 de junho de 1993 (leia-se dispensa do processo licitatório) e a alteração do instrumento jurídico (de convênios para contratos) usados nos serviços de ATER, instituindo as chamadas públicas (Avila et al., 2015).

${ }^{7}$ No ano de 2010 o DATER também lançou um edital para apoiar a estruturação de Núcleos de Pesquisa e Extensão em Agroecologia (NEAs), que deveriam se embasar na PNATER. Através dos NEAs,procurase ampliar a produção científica no campo da agroecologia,realizando ações articuladas voltadas ao ensino, à pesquisa e à extensão junto aos agricultores familiares, qualificando, também, a formação de professores, pesquisadores, estudantes e profissionais de ATER.
} 
organizações da sociedade civil, a Embrapa construiu um Marco Referencial da Agroecologia. Lançado em 2006, este documento deu consistência ao processo de institucionalização da agroecologia no âmbito desta instituição, contribuindo para fortalecer uma rede de pesquisadores dedicados à pesquisa em agroecologia. $O$ texto também estabeleceu uma diferenciação entre a agroecologia como um referencial teórico, baseado em um enfoque sistêmico, e as diversas "agriculturas ecológicas" empiricamente existentes.

A criação de programas públicos voltados à aquisição e distribuição de alimentos oriundos da agricultura familiar constituiu-se também, como uma inovação importante nesse período, com destaque para o Programa de Aquisição de Alimentos (PAA), instituído em 2003, e para o Programa Nacional de Alimentação Escolar (PNAE), reconfigurado em 2009. Por meio do PAA, o Governo Federal utiliza mecanismos simplificados de aquisição pública para compra de alimentos de agricultores familiares. Esses alimentos são fornecidos para pessoas em situação de vulnerabilidade social, equipamentos públicos de alimentação e nutrição, instituições socioassistenciais e escolas da rede pública ou filantrópica de ensino. Além disso, também podem ser destinados à formação de estoques públicos de alimentos.

$\mathrm{O} \mathrm{PAA}^{8}$ constituiu-se como um elo importante entre a política agrícola e as políticas sociais voltadas à garantia da SAN. Na medida em que possibilita a articulação entre os sistemas produtivos diversificados da agricultura familiar e a demanda oriunda do mercado institucional, o programa contribui para promover a diversidade dos sistemas produtivos, chegando a adquirir, em 2012, 380 itens diferenciados de alimentos. O regulamento que orienta o PAA permite a aquisição de alimentos orgânicos/agroecológicos com preços diferenciados de até 30\%. O percentual de alimentos certificados adquiridos através do PAA não assumiu, no entanto, dimensões muito expressivas, representando, em 2012 (ano em que o PAA apresentou seu melhor desempenho), cerca de $2 \%$ do volume total de aquisições (Porto, 2016). O desenho do programa possibilita, também, a compra e distribuição de sementes crioulas, sendo que a aquisição de sementes através do mercado institucional potencializou importantes ações voltadas ao fortalecimento de bancos comunitários de sementes geridos pelos agricultores familiares.

O PNAE, por sua vez, tem por objetivo garantir a alimentação de estudantes da rede pública ou filantrópica de ensino durante o período letivo. Este programa tem suas origens na década de 1950, tendo sido, inicialmente, institucionalizado como Campanha de Merenda Escolar (CME). Sua inscrição neste esforço de compilação de programas e ações em favor da agroecologia se deve, sobretudo, às alterações realizadas no Programa em 2009, quando se definiu que pelo menos $30 \%$ dos recursos destinados ao PNAE deveriam ser utilizados na aquisição direta de gêneros alimentícios da agricultura familiar. A coordenação do PNAE compete à União, que repassa recursos aos Estados, Distrito Federal e Municípios, por meio da autarquia do Fundo Nacional de Desenvolvimento da Educação (FNDE). Seu regulamento procura priorizar a compra de produtos orgânicos ou agroecológicos (com 15 a 30\% de aumento do preço de compra), como também os produzidos no município ou região em que estão localizadas as instituições demandantes. A garantia de comercialização

\footnotetext{
${ }^{8}$ A experiência do PAAe PNAE influenciou a publicação do Decreto 8.473 de junho de 2015 que estabelece a exigência de aquisição mínima de 30\% de gêneros da agricultura familiar por toda a administração pública.
} 
oferecida contribui para a diversificação dos sistemas produtivos dos agricultores, ampliando, assim, as possibilidades de aplicação de princípios e práticas agroecológicas.

Finalmente, destacaram-se na pesquisa o Programa Um Milhão de Cisternas Rurais (P1MC), criado em 2003, e o Programa Uma Terra e Duas Águas $\left(P_{1}+2\right)$, constituído em 2007, como exemplos da interlocução entre a sociedade civil organizada e o Estado na construção e operacionalização de políticas públicas. 0 $\mathrm{P} 1 \mathrm{MC}$ visa garantir o acesso à água de qualidade para o consumo familiar por meio da construção de cisternas de placas de cimento com capacidade de armazenamento de 16 mil litros de água da chuva, as quais são instaladas ao lado das residências das famílias rurais. O P1+2 busca fortalecer os efeitos do $\mathrm{P} 1 \mathrm{MC}$, adicionando às cisternas construídas para o abastecimento humano uma "segunda água (+2)", que é a voltada à produção agrícola e abastecimento animal. Estes programas podem ser considerados como um dos resultados da consolidação da proposta de Convivência com o Semiárido (em oposição às tradicionais políticas de Combate à Seca), a qual foi construída por um amplo conjunto de organizações da sociedade civil que se congregam na Articulação Semiárido Brasileiro (ASA), a qual tornou o P1MC e o P1+2 parte integrante do seu Programa de Formação e Mobilização Social para a Convivência com o Semiárido. Estes programas possibilitam às famílias desenvolver iniciativas de manejo e gestão com vistas a potencializar o aumento e a estabilização da oferta hídrica nos sistemas produtivos a partir de um enfoque agroecológico, à exemplo dos bancos de sementes, sistemas agroflorestais e dos quintais produtivos. Não obstante, o que mais chama a atenção nestes programas é o fato de considerarem os processos de mobilização e organização como parte integrante das tecnologias sociais utilizadas para a promoção da agroecologia. 


\section{A construção da Política e dos Planos Nacionais de Agroecologia e Produção Orgânica}

Durante o Governo Dilma Roussef, o principal foco tanto das redes de agroecologia como de segmentos importantes ligados à produção orgânica foi a construção da Política Nacional de Agroecologia e Produção Orgânica (PNAPO), a qual foi instituída pelo Decreto 7.794/2012, e dos Planos Nacionais de Agroecologia e Produção Orgânica (PLANAPOs), 2013-2015 e 2016-2019. O processo de formulação da PNAPO desencadeou todo um esforço de articulação e construção de convergências entre organizações sociais e gestores públicos com intervenção tanto no campo da agroecologia, como no universo da agricultura orgânica. Não cabe aqui detalhar os múltiplos processos que possibilitaram que o tema da agroecologia ganhasse visibilidade na agenda política do primeiro governo Dilma Rousseff, desdobrando-se na formulação de uma Política Nacional que articula diferentes Ministérios.

O protagonismo dos movimentos de mulheres organizados na Marcha das Margaridas foi, sem dúvida, um componente fundamental nesse processo. As jornadas denominadas Marchas das Margaridas, lideradas historicamente, pela Confederação Nacional dos Trabalhadores na Agricultura (CONTAG), articulam um amplo conjunto de organizações de mulheres, em parceria com outros atores. As Marchas ocorrem, aproximadamente, de quatro em quatro anos, sendo que a primeira delas foi organizada no ano 2000. Em 2011 o lema principal da Marcha foi sintetizado na frase "2011 razões para marchar por desenvolvimento sustentável com justiça, autonomia, liberdade e igualdade." No encerramento da Marcha, que reuniu milhares de mulheres, a Presidente Dilma Rousseff comprometeu-se com a criação de um grupo especial de trabalho para elaborar um Programa Nacional de Agroecologia. (Aguiar, 2015; Moura, 2016).

O Ministério do Meio Ambiente foi o órgão designado pelo Governo para coordenar o processo de construção da nova política, constituindo-se, na sequência, um Grupo Interministerial para tratar deste tema, com estreito acompanhamento da Secretaria Geral da Presidência da República (SG-PR). A densidade social alcançada pela agroecologia, repercutindo em um cenário político e institucional favorável, permitiu que este processo ganhasse dinamismo. Mas é importante, também, levar em consideração a relativa visibilidade alcançada pela agricultura orgânica nas ações do MAPA. Como observa Moura (2016), estava em construção, no âmbito da Comissão Nacional de Produção Orgânica (CNPOrg), envolvendo, também, as Comissões de Produção Orgânica (CPOrgs) nos estados, a formulação de uma política mais ampla, voltada à produção orgânica, que vinha sendo discutida desde o segundo mandado do Presidente Lula. A janela de oportunidades aberta com a PNAPO foi percebida como uma oportunidade para que esta proposta pudesse avançar. $O$ esforço de mediação desenvolvido pelo MMA, no intuito de aproximar redes e movimentos do campo da agroecologia e organizações ligadas à agricultura orgânica foi bem-sucedido e possibilitou que estas iniciativas pudessem convergir.

No campo das organizações da sociedade civil, a construção da PNAPO foi um momento importante de sistematização, não apenas de uma concepção compartilhada de agroecologia, mas de uma ampla agenda de políticas públicas nas mais diferentes áreas. A Articulação Nacional de Agroecologia (ANA) desempenhou um papel fundamental no sentido de articular um processo de diálogo entre as 
diferentes organizações, contando com o suporte financeiro do Governo Federal para a realização de encontros nas diferentes regiões do país e de um seminário em nível nacional. Esse debate mobilizou aproximadamente 300 pessoas e 133 organizações, incluindo representantes dos movimentos sociais, ONGs, redes regionais e estaduais de agroecologia e profissionais vinculados a universidades e órgãos governamentais de pesquisa e extensão.

Para essas organizações, a nova política "em suas concepções, instrumentos, mecanismos de gestão e controle social, deve estar orientada para o fortalecimento de uma alternativa sustentável aos padrões atualmente dominantes na organização socioeconômica, técnica e ecológica do desenvolvimento rural brasileiro" (ANA, 2012, p. 2). Neste sentido, "a PNAPO não é redutível a uma mera política ambiental, nem à promoção de um conjunto de técnicas ou boas práticas", "não se restringe à promoção de nichos de mercado de poucos agricultores/as para poucos/as consumidores/as", "tampouco pode se reduzir a ações compensatórias destinadas a pobres rurais desinseridos dos grandes mercados" (ANA, 2012, p. 2-3). A linha divisória estabelecida pelos atores sociais ligados ao campo agroecológico entre a agroecologia e a agricultura orgânica aparece explicitada no documento. É interessante perceber, ao mesmo tempo, que estas diferenças conseguiram ser equacionadas, em boa medida, na construção do Plano, em um ambiente de respeito às diferentes identidades.

A partir dos delineamentos da PNAPO, o Plano Nacional de Agroecologia e Produção Orgânica (PLANAPO) previu, em sua primeira fase, um total de 125 ações e um investimento de $\mathrm{R} \$ 8,8$ bilhões em ações de promoção da agroecologia, subdivididas em quatro objetivos estratégicos: (a) produção, uso e conservação dos recursos naturais, (b) conhecimentos, (c) comercialização e (d) consumo. ${ }^{9}$ Apesar dos números vultosos, o PLANAPO I envolveu basicamente a coordenação de programas que já existiam em vários ministérios, incluindo MDA e MAPA. Mesmo assim, entre os avanços cabe mencionar a articulação entre os diferentes movimentos e organizações sociais e entre "produtores orgânicos" e agroecológicos, o envolvimento de um número crescente de Ministérios, o fortalecimento do programa Ecoforte $^{10}$ e o exercício de monitoramento do programas e ações de políticas públicas desenvolvido através da CNAPO, focado sobretudo, até o presente momento, no cumprimento das metas físicas dos diferentes programas. Por outro lado, as tentativas de institucionalizar o Programa Nacional de Redução do Uso de Agrotóxicos (PRONARA) tem encontrado inúmeras resistências protagonizadas por atores governamentais e não governamentais.

\footnotetext{
${ }^{9}$ Ações relacionadas à reforma agrária e direitos territoriais, que aparecem de forma destacada no documento coordenado pela ANA não ganharam um lugar de destaque no I PLANAPO. O II PLANAPO contempla, no entanto, em seu Eixo 5 o tema "Terra e Território"

${ }^{10}$ O Programa Ecoforte tem como objetivo o fortalecimento e ampliação das redes, cooperativas e organizações socioprodutivas voltadas à agroecologia, extrativismo e produção orgânica. Já vinha sendo discutido com a Secretaria de Governo da Presidência da República (SG-PR), a Fundação Banco do Brasil (FBB), o Banco Nacional de Desenvolvimento Econômico e Social (BNDES) e diferentes Ministérios, através de um processo de articulação sem vínculo direto, pelo menos inicialmente, com os debates relativos à formulação da PNAPO. Verifica-se, a partir de um certo momento, uma crescente sinergia entre esses dois processos.
} 


\section{Figura 1. Construção de políticas públicas para a agroecologia no Brasil.}

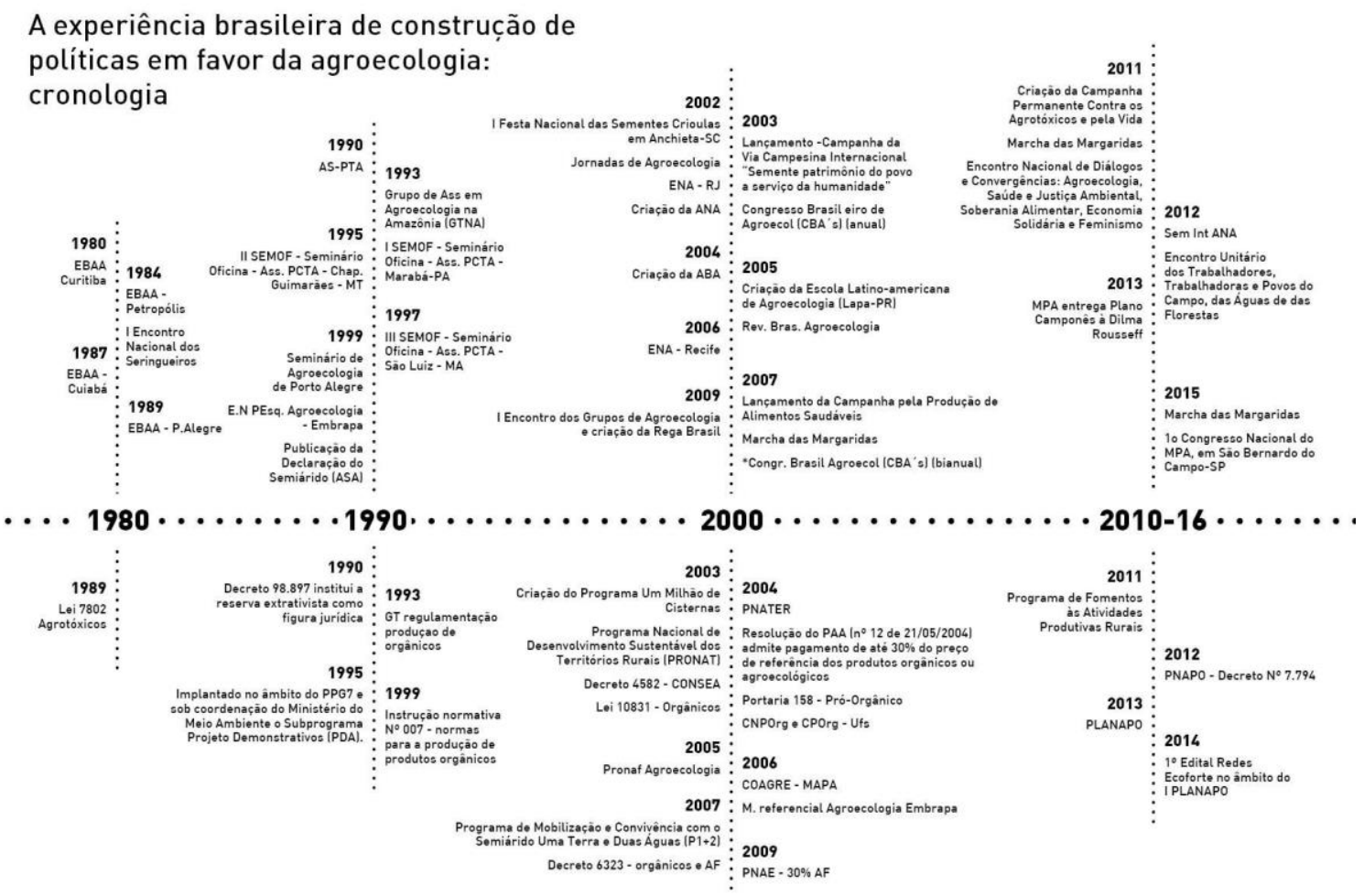

Fonte: Schmidt et al. (2017).

A principal inovação foi a criação de uma nova estrutura de governança, composta por dois espaços: (a) Câmara Interministerial de Agroecologia e Produção Orgânica (CIAPO) - abarcando uma dezena de órgãos governamentais; e (b) Comissão Nacional de Agroecologia e Produção Orgânica (CNAPO) - órgão de composição paritária entre governo e sociedade civil, onde estão os principais movimentos sociais rurais e agroecológicos acima referidos, representações da agricultura orgânica, assim como as associações de pesquisadores e extensionistas rurais, mas com a notável ausência dos setores agroempresariais. A PNAPO buscou adotar uma perspectiva intersetorial, articulando diferentes ministérios e mobilizando, além disso, um conjunto diferenciado de organizações sociais e instituições. No entanto, muitos instrumentos de política pública não foram pensados, originalmente, como ferramentas de promoção da agroecologia. O ajuste destes dispositivos com base em um novo enfoque demanda, necessariamente, uma série de modificações tanto do ponto de vista normativo como no que se refere às suas formas de implementação.

\section{Considerações finais}

A incorporação da agroecologia como um enfoque de políticas públicas foi resultado de uma longa trajetória de interações entre movimentos sociais e redes de articulação da sociedade civil com o poder público, resultando, ao longo do tempo, em uma pluralidade de processos de institucionalização da agroecologia. Estas iniciativas culminaram, em 2012, com a construção da PNAPO e do PLANAPO. Chama atenção, nessa trajetória, a relevância assumida por fóruns e arenas de participação 
social na construção de um movimento de crítica e contestação dos efeitos gerados pelo processo de modernização da agricultura e na produção de um enfoque alternativo. Estes espaços de participação foram fundamentais no alinhamento dos diferentes atores do campo agroecológico e na construção de convergências, não apenas no âmbito das redes de agroecologia, mas, destas, com as organizações vinculadas ao universo da agricultura orgânica.

O referencial de ação pública proposto pelos movimentos em torno da agroecologia avançou nas possibilidades abertas pelo reconhecimento da agricultura familiar e pela implementação de um conjunto diversificado de políticas públicas voltadas a este setor. É possível identificar, no entanto, complementaridades mas, também, descontinuidades entre $\mathrm{O}$ enfoque adotado pelas políticas de fortalecimento da agricultura familiar e a abordagem proposta pela agroecologia, decorrentes, entre outros fatores, das fortes conexões estabelecidas por determinados segmentos da agricultura familiar brasileira com as cadeias globais de commodities. Cabe observar, ao mesmo tempo, que a forte presença do agronegócio, que se manifesta em termos políticos, econômicos e territoriais, apresenta-se como um obstáculo à implantação de uma política de promoção da agroecologia capaz de reorientar, de uma forma mais profunda, as políticas de desenvolvimento rural.

O debate em torno da agroecologia tencionou os limites políticos, institucionais e práticos de coexistência entre as duas agriculturas (agronegócio e agricultura familiar). Com a PNAPO, a agroecologia se apresentou como uma abordagem intersetorial, a qual busca redirecionar um conjunto heterogêneo de instrumentos de política pública a partir de um novo referencial, enfrentando, neste movimento, uma série de desafios relacionados à adequação, articulação e coordenação do amplo leque de programas e ações incorporados a esta política. As profundas mudanças de cenário ocorridas desde 2016 e relacionadas ao processo de impeachment da presidenta Dilma Rousseff não nos permitem prospectar cenários. Lançado em julho de 2016, o II Plano Nacional de Agroecologia e Produção Orgânica é a expressão da instabilidade deste referencial, que não parece ter o mesmo nível de ressonância dentro do novo governo. A extinção das políticas de desenvolvimento territorial, a redução dos programas de extensão rural, o fim dos núcleos de agroecologia e a reestruturação da Embrapa são exemplos de uma profunda ruptura no que diz respeito ao reconhecimento da agroecologia como referencial de políticas públicas.

\section{REFERÊNCIAS}

AGUIAR, V. V. P. Somos todas Margaridas: um estudo sobre o processo de constituição das mulheres do campo e da floresta como sujeito político. Tese (Doutorado em Ciências Sociais), Instituto de Filosofia e Ciências Humanas. Campinas-SP, Universidade Estadual de Campinas, UNICAMP, 2015.

ALEGRETTI, M. H. A construção social de políticas ambientais: Chico Mendes e o movimento dos seringueiros. Tese (Doutorado em Desenvolvimento Sustentável Gestão e Política Ambiental), Centro de Desenvolvimento Sustentável. Brasília-DF, Universidade de Brasília, UNB, 2002. 
ALMEIDA, A. W. B. D. Agroestratégias e desterritorialização: direitos territoriais e étnicos na mira dos estrategistas dos agronegócios. In: ALMEIDA, A. W. B. D. et al Capitalismo globalizado e recursos territoriais. Rio de Janeiro: Lamparina, 2010. p. 101-143.

ALTIERI, M. As bases científicas da agricultura alternativa. Rio de Janeiro: PTA/FASE, 1989.

ALVES, G. Crise do Neodesenvolvimentismo e Estado neoliberal no Brasil: elementos de análise de conjuntura do capitalismo brasileiro. In: CORSI, F. L.; CAMARGO, J. M.; SANTOS, A. dos. (org.) A conjuntura econômica e política brasileira e argentina. Marília: Oficina Universitária; São Paulo: Cultura Acadêmica, 2015. p. 25-48.

AVILA, M. L.; ASSAD, S. S. ; SOARES, M. G. P. ; SOUZA, C. S. ; SOUZA, R. M. . Nova lei de ATER e inovações em políticas públicas: o caso do Programa Mais Gestão. In: $7^{\circ}$ ENCONTRO NACIONAL DA ANPPAS, Anais... Brasilia. Anppas, 2015.

AVRITZER, L. Instituições participativas e desenho institucional: algumas considerações sobre a variação da participação cidadã no Brasil democrático. Opinião Pública, v. 14, n. 1, 2008. p. 43-64.

BARCELLOS, S. B. A apropriação do discurso da agroecologia pelo Movimento dos Trabalhadores Rurais Sem Terra (MST). Sociedade e Desenvolvimento Rural, v. 8, n. 1, jan. 2014, p. 1-25.

BRASIL. CÂMARA INTERMINISTERIAL DE AGROECOLOGIA E PRODUÇÃO ORGÂNICA - CIAPO. Plano Nacional de Agroecologia e Produção Orgânica - PLANAPO. Relatório de Balanço 2013-2015. Brasília, setembro de 2016.

BRASIL. Constituição da República Federativa do Brasil. Brasília, DF: Senado, 1988.

BRASIL. MINISTÉRIO DA AGRICULTURA, PECUÁRIA E ABASTECIMENTO. Plano setorial de mitigação e de adaptação às mudanças climáticas para a consolidação de uma economia de baixa emissão de carbono na agricultura: plano $A B C$ (Agricultura de Baixa Emissão de Carbono). Brasília: MAPA/ACS, 2012.

BRASIL. MINISTÉRIO DO DESENVOLVIMENTO AGRÁRIO. Brasil Agroecológico: Plano Nacional de Agroecologia e Produção Orgânica - Planapo: 2016-2019. Brasília : MDA, 2016.

BRASIL. MINISTÉRIO DO DESENVOLVIMENTO AGRÁRIO, SAF/DATER. Política Nacional de Assistência Técnica e Extensão Rural. Brasil, maio de 2004.

CAPORAL, F. R.; COSTABEBER, J. A. Agrocologia e Desenvolvimento Rural Sustentável: perspectivas para uma nova extensão rural. Revista Agroecologia e Desenvolvimento Rural Sustentável, v. 1, n. 1, jan./mar. 2000. p. 16-37. 
CUNHA, P. R. O Código Florestal e os processos de formulação do mecanismo de compensação de Reserva Legal (1996-2012): ambiente político e política ambiental. Dissertação (Mestrado em Ciência Ambiental), Programa de Pós-Graduação em Ciência Ambiental. São Paulo-SP, Universidade de São Paulo, USP, 2013 b.

DELGADO, G. C. Do capital financeiro na agricultura à economia do agronegócio: mudanças cíclicas em meio século (1965-2012). Porto Alegre: UFRGS, 2012.

DELGADO, G. C. Questão agrária hoje. In: DELGADO, G. C.; BERGAMASCO, S. M. P. P. Agricultura familiar brasileira: desafios e perspectivas de futuro. Brasília: SEAD, 2017. p. 12-23.

DIAS, M. M. As ONGs e a construção de alternativas para o desenvolvimento rural: um estudo a partir da Assessoria e Serviços a Projetos em Agricultura Alternativa (AS-PTA). Tese (Doutorado em Desenvolvimento, Agricultura e Sociedade), Universidade Federal Rural do Rio de Janeiro, UFRRJ, 2004.

EMBRAPA. Visão 2014-2034: o futuro do desenvolvimento tecnológico da agricultura brasileira: síntese / Embrapa. Brasília-DF : Embrapa, 2014.

FARRANHA, A. C.; SANTOS, V. S. dos. Ativismo em redes sociais digitais: análise da Rede Cerrado e suas interfaces na promoção de política públicas sustentáveis.

Revista Direitos Emergentes na Sociedade Global. v. 4, n.1, 2015.

FERREIRA, B.; ALVES, F.; CARVALHO FILHO, J. J. de. Constituição vinte anos: caminhos e descaminhos da reforma agrária - embates (permanentes), avanços (poucos), derrotas (muitas). In: IPEA. Políticas sociais: acompanhamento e análise. Vinte anos da Constituição Federal, n. 17, v. 2, 2009, p. 155-223.

FONSECA, M.F. de A. C. A institucionalização do mercado de orgânicos no mundo e no Brasil: uma interpretação. Tese (Doutorado em Sociologia, Área de Concentração Desenvolvimento e Agricultura), Universidade Federal Rural do Rio de Janeiro, UFRRJ, 2005.

GRISA, C. Políticas públicas para a agricultura familiar no Brasil: produção e institucionalização das ideias. Tese (Doutorado em Ciências Sociais em Desenvolvimento, Agricultura e Sociedade), Universidade Federal Rural do Rio de Janeiro, UFRRJ, 2012.

GRISA, C. A agricultura familiar nas políticas para a agricultura familiar. In: DELGADO, G. C.; BERGAMASCO, S. M. P. P. Agricultura familiar brasileira: desafios e perspectivas de futuro. Brasília: SEAD, 2017. p. 292-313.

LASCOUMES, P. Rendre gouvernable: de la "traduction" au "transcodage": I'analyse des processus de changement dans les réseaux d'action publique. In: CURAP. La Gouvernabilité. Paris: PUF, 1996. p. 325-338. 
LEROY, J. P.; ABRAMOVAY, R. Avaliação Rede PTA - Relatórios. Setembro de 1998.

LUZZI, N. O debate agroecológico no Brasil: uma construção a partir de diferentes atores sociais. Tese (Doutorado em Ciências Sociais em Desenvolvimento, Agricultura e Sociedade), Universidade Federal Rural do Rio de Janeiro, UFRRJ, 2007.

MAHONEY J.; RUESCHEMEYER D. Comparative Historical Analysis in the Social Sciences. New York: Cambridge University Press, 2003.

MAHONEY J., THELEN K. (Eds.). Explaining institutional change: Ambiguity, agency, and power. New York: Cambridge University Press, 2010.

MATTOS, L. A. A Análise do Proambiente como Política Pública Federal para a Amazônia Brasileira. Cadernos de Ciência \& Tecnologia, v. 28, n. 3, p. 721-749, 2011.

MEIRELLES, L. Certificação e Dominação. Ipê: Centro Ecológico, 1994. Disponível em:

http://www.centroecologico.org.br/certificacao_download.php?id_pdfcertificacao= 71\&tipo=pdf. Acesso em: 28 mar. 2017.

MONTE, F. C. D. O INCRA e a Política de Assentamentos Rurais: um estudo sobre processos político-administrativos de ação pública. Tese (Doutorado em Ciências Sociais em Desenvolvimento, Agricultura e Sociedade), Universidade Federal Rural do Rio de Janeiro, UFRRJ, 2013.

MOURA, I. F. de. Agroecologia na agenda governamental brasileira: trajetórias no período 2003-2014. Tese (Doutorado em Ciência, Tecnologia e Inovação em Agropecuária), Universidade Federal Rural do Rio de Janeiro, UFRRJ, 2016.

MULLER, P. Esquisse d'une théorie du changement dans l'action publique. Structures, acteurs et quadres cognitifs. Revue Française des Sciences Politique, v. 55, p. 155-187, 2005.

OECD-FAO. OECD-FAO Agricultural Outlook 2015. Paris: OECD Publishing, 2015.

OXFAM - Brasil Terrenos da desigualdade: terra, agricultura e desigualdades no Brasil Rural. Oxfam, 2017.

PALIER B., SUREL Y. Les «trois I» et l'analyse de l'État en action. Revue Française de Science Politique, v. 55, n. 1, p. 7-32, 2005.

PETERSEN, P.; MUSSOI, E.; DAL SOGLIO, F. Institutionalization of the agroecological approach in Brazil: advances and challenges. Agroecology and Sustainable Food Systems, v. 37, n. 1, p. 103-114, 2013. 
PIERSON P.; SCKOPOL T. El institucionalismo histórico en la ciencia política contemporânea. Revista Uruguaia de Ciencia Política v. 17, n. 1, p. 7-38, 2008.

PIRES, R. R. C.; VAZ, A. C. N. Para além da participação: interfaces socioestatais no Governo Federal. Lua Nova, n. 93, p. 61-91, 2014.

PICOLOTTO, E.; BRANDENBURG, A. Uma grande oportunidade: o sindicalismo e seus projetos de ecologização da agricultura familiar. Ambiente \& Sociedade, v. 18, p. 1-18, 2015.

PORTO, J. R. S. Poder e território no Baixo Sul da Bahia: os discursos e os arranjos políticos de desenvolvimento. Tese (Doutorado em Ciências Sociais em Desenvolvimento, Agricultura e Sociedade), Universidade Federal Rural do Rio de Janeiro, UFRRJ, 2016.

PORTO, S. A agroecologia e o Programa de Aquisição de Alimentos (PAA). Carta Maior, 14/06/2016. Disponível em: http://cartamaior.com.br/?/Editoria/ MeioAmbiente/A-agroecologia-e-o-Programa-de-Aquisicao-de-Alimentos-PAA/3/36284 . Acesso em: 31/10/2016.

SABATIER P. A., JENKINS-SMITH H. C. (Eds) Policy Change and Learning: An Advocacy Coalition Approach. Theoretical Lenses on Public Policy. Boulder: San Fransisco, Oxford: Westwiew Press, 1993

SABOURIN E., PATROUILLEAU M. M., LE COQ J.-F., VAZQUEZ L., NIEDERLE P.-A. (Eds.). Políticas Públicas a favor de la Agroecología en América Latina y el Caribe. Porto Alegre, Rede PP-AL, FAO, 2017.

SAMBUICHI, R. H. R.; OLIVEIRA, M. A. C. Análise das linhas de crédito do Pronaf para o desenvolvimento sustentável da agricultura familiar. Cadernos de Agroecologia, v. 6, n. 2, p. 1-6, 2011.

SANTILLI, J. Socioambientalismo e novos direitos. São Paulo: Peirópolis, 2005.

SILIPRANDI, E. Desafios para a extensão rural: o social na transição agroecológica. Revista Agroecologia e Desenvolvimento Rural Sustentável, v. 3, n. 3, p. 38-48, 2002.

SUREL Y. Idées, intérêts, institutions dans l'analyse des politiques publiques. Pouvoir, n. 87, p. 161-178, 1998.

WEID, J. M. von der. As práticas inovadoras: identificação, sistematização, difusão. Proposta: experiências em educação popular, v. 36, p. 8-13, 1988.

WEID, J. M. von der. Texto de referência do campo agroecológico para a conferência nacional de ATER. Rio de Janeiro, ASPTA, 2011. 
WEIBLE C. M., SABATIER P. A., MCQUEEN K. Themes and Variations: Taking Stock of the Advocacy Coalition Framework. Policy Studies Journal, v. 37, n. 1, p. 121-140, 2009.

Paulo André Niederle. Doutor em Ciências Sociais pela Universidade Federal Rural do Rio de Janeiro. Professor dos Programas de Pós-graduação em Sociologia (PPGS) e Desenvolvimento Rural (PGDR) da Universidade Federal do Rio Grande do Sul (UFRGS). pauloniederlegmail.com

Eric Sabourin. Doutor em Antropologia e Etnologia pela Université Paris Diderot. Pesquisador do Centro de Cooperação Internacional em Pesquisa Agronômica para o Desenvolvimento (CIRAD) e da Universidade de Brasília (UnB).

Claudia Job Schmitt. Doutora em Sociologia pela Universidade Federal do Rio Grande do Sul. Professora do Programa de Pós-Graduação de Ciências Sociais em Agricultura, Desenvolvimento e Sociedade da Universidade Federal Rural do Rio de Janeiro (CPDA-UFRRJ).

Mario Lúcio de Ávila. Doutor em Desenvolvimento Sustentável pela Universidade de Brasília. Professor dos Programas de Pós Graduação em Gestão Pública (PPGP) e de Meio Ambiente e Desenvolvimento Rural (MADER) da Universidade de Brasília (UnB).

Paulo Petersen. Doutor em Estudos Ambientais pela Universidad Pablo de Olavide. Coordenador-executivo da ONG AS-PTA - Agricultura Familiar e Agroecologia, vice-presidente da Associação Brasileira de Agroecologia (ABA).

William Santos de Assis. Doutor em Desenvolvimento, Agricultura e Sociedade pela Universidade Federal Rural do Rio de Janeiro. Professor do Programa de Pósgraduação em Agriculturas Amazônicas (PPGAA) da Universidade Federal do Pará (UFPA). 